\title{
A TRADUTORA E O DIÁLOGO INTERMIDIÁTICO EM ANTIGONICK DE ANNE CARSON
}

\author{
Rodrigo Tadeu Gonçalves* \\ Julia Nascimento**
}

Recebido em: 23/01/2019

Aprovado em: 09/03/2019

RESUMO: Antigonick (2012) é a tradução da dramaturga, escritora e tradutora canadense Anne Carson para a tragédia Antígona de Sófocles. No prefácio "the task of the translator of antigone", em forma de carta/ poema direcionada à personagem Antígona, aparecem comentários sobre encenações anteriores, mais especificamente sobre as montagens de Bertolt Brecht e Jean Anouilh, além da composição 4’33”, de John Cage. Este artigo pretende discutir como essas referências intertextuais e intermidiáticas contribuem para uma leitura que englobe a vasta tradição de recepção dos clássicos sem deixar de considerar as particularidades do trabalho da tradutora e do seu comprometimento com a "mulher de palavra”, Antígona. A fim de pensar o diálogo intermidiático no prefácio, utilizam-se especialmente as discussões propostas por Anne Ubersfeld no texto A representação dos clássicos: reescritura ou museu (1978) e o conceito de tradução intersemiótica presente em "Estudos interartes: conceitos, termos, objetivos" (1997) de Claus Clüver. Acredita-se que uma análise atenta do prefácio possa oferecer pistas importantes sobre o processo criativo e sobre a proposta/projeto de tradução empreendido por Carson.

PALAVRAS-CHAVE: intermidialidade; recepção dos clássicos; Anne Carson.

\section{THE WOMAN TRANSLATOR AND THE INTERMEDIA DIALOGUE IN ANNE CARSON'S ANTIGONICK}

* Professor de Língua e Literatura Latina, Universidade Federal do Paraná.

goncalvesrt@gmail.com

** Doutoranda em

Estudos Literários,

Universidade Federal

do Paraná.

ju_raiz@yahoo.com.br 
references contribute to a reading which encompasses the vast tradition of receptions of the classics without failing to consider the particularities of the translator's work and her compromise with the "woman of word", Antigone. In order to conceptualize the intermedia dialogue of the preface we make use especially of Ubersfeld's text $A$ representação dos clássicos: reescritura ou museu (1978) and the concept of intersemiotic translation present in "Estudos interartes: conceitos, termos, objetivos" (1997) by Claus Clüver. We believe that a close analysis of this preface can offer important ideas about the creative process and the project of translation carried out by Carson.

KEYWORDS: intermediality; Classical receptions; Anne Carson.

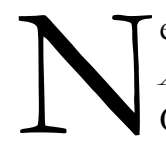

este artigo, empreendemos uma análise da reescrita/tradução/adaptação de Antigonick (editada em 2012) da escritora, tradutora e dramaturga canadense Anne Carson (1950-), com foco nas questões intertextuais e intermidiáticas levantadas pelas reflexões da dramaturga especialmente em seu prefácio de tradutora, visto que uma análise completa da peça demandaria mais espaço do que um artigo poderia abarcar. No entanto, conforme argumentaremos, o prefácio dá pistas importantes sobre o processo criativo e sobre a própria proposta/projeto de tradução empreendido por Carson. ${ }^{1}$

A primeira questão que a leitura do prefácio suscita é: onde começa a autoria da tradutora? Qual é o grau de autoconsciência criadora atrelado ao gesto tradutório aparentemente convencional proposto por Carson? É preciso considerar que, na capa tanto da primeira edição, de 2012, em capa dura, quanto da edição em paperback da New Directions, de 2015, consta em primeiro plano o título Antigonick (tipograficamente separado em "ANTIGO" e "NICK", nome de um personagem acrescentado por Carson à peça grega), logo abaixo, o nome de Sófocles grafado entre parênteses com ortografia transliterada do grego, "(SOPHOKLES)", figurando, portanto, como autor e o de Anne Carson como tradutora abaixo à esquerda (além do nome da ilustradora, Bianca Stone, na versão de 2012). Tal disposição tipográfica parece considerar o texto como tradução de Sófocles.

Os parênteses, contudo, desestabilizam o processo de autoria, na medida em que, inclusive, tanto o título da peça é recriado quanto o rol de personagens, bem como diversos procedimentos de reescrita de caráter mais intervencionista figuram ao longo do texto (Eurídice, por exemplo, no episódio 5, inicia sua primeira fala com "this is Eurydike's monologue / it's her only speech in the play / you may not know who she is / that's okay", e a termina com "exit Euridike bleeding from all orifices", seguido da rubrica "[Eurydike does not exit]", p. 39-40). Embora procedimentos como esse, profundamente metateatrais e autoconscientes, povoem o texto, há na sequência de episódios e cantos corais a manutenção da estrutura e ordenação exatas da peça de Sófocles, indicadas inclusive pelos números de versos. Após poucas páginas de leitura ou pouco tempo de encenação da peça, percebe-se

\footnotetext{
${ }^{1}$ Anne Carson, além de tradutora, é helenista, poeta e ensaísta, e entre suas traduções e versões de textos antigos, encontramos Safo (If Not, Winter, 2002), Electra (2001), Ifigênia entre os Tauros (2014) e As Bacantes (Bakekhai, 2017), entre outras.
} 
que se está lidando com uma recriação adaptativa, uma reescrita dramatúrgica que se utiliza de procedimentos paródicos autoconscientes de seu estatuto de texto traduzido e de texto original simultaneamente. Ou seja, a peça de Carson pretende ser ao mesmo tempo uma tradução de Sófocles e uma nova criação, sem precisar tomar decisão clara a respeito, o que lhe confere estatuto de alto grau de sofisticação enquanto recepção de uma tragédia ática (o que não é exclusividade de Carson, como veremos abaixo na discussão do prefácio).

O prefácio da tradutora em Antigonick é construído em intertextualidade explícita com a peça de Sófocles, além de produzir um certo grau de desestabilização no gênero "prefácio da tradutora". Isso porque Carson prescinde de discutir especificamente suas escolhas tradutórias ou de apresentar seu projeto de tradução de forma mais convencional e produz uma carta em versos direcionada à personagem Antígona, intitulada the task of the translator of antigone, que estabelece um diálogo intermidiático com outras encenações anteriores do mito clássico e outros/as autores/as, dramaturgos/as, compositores/as e filósofos/as relevantes para a própria história da recepção da peça de Sófocles (tais como Hegel, Lacan e Judith Butler).

As principais referências artísticas são três: as encenações de Antigone de Bertolt Brecht e de Jean Anouilh e a referência à famosa composição (não) sonora de John Cage intitulada 4'33". A partir daqui, nosso objetivo principal será pensar como esse diálogo intermidiático - escrita, imagens e (não) sons - pode abrir novas possibilidades de ler o texto traduzido de Carson.

Em Antigonick, é possível ler o prefácio em comparação com o prólogo, elemento da tragédia clássica grega, responsável pelo contexto inicial, estabelecendo a ambientação e o tom da peça. No caso de Antígona, inclusive, a alteração proposta pelo prólogo de Sófocles em que as irmãs Antígona e Ismene dialogam fora do espaço cênico convencional de uma tragédia ática (à frente de um palácio, o espaço público), gerando uma variação dramatúrgica em que o diálogo em questão aparece como se se tratasse de um longo aparte à peça, um diálogo privado ocorrido diante dos espectadores, possibilita que o prefácio de Carson explore antecedentes ao enredo e a linhagem de recepção e crítica da própria peça fora da peça, embora escrito com o mesmo estilo de versos livres que serão usados ao longo da peça - gerando, mais uma vez, instabilidade quanto ao que pertence diretamente ao texto dramatúrgico e o que não (rubricas, prefácios, tudo em Carson parece ser feito para o palco). Além disso, o prefácio funciona de diversas maneiras: como crítica teatral, ao recuperar referências teatrais de encenações anteriores pensando qual é mais "eficiente"; como mapa de leitura poético, já que revela parte do processo da leitura de Anne Carson da peça de Sófocles; como estudo de método, uma vez que expõe parte do projeto de tradução que a dramaturga constrói. Tendo as funções do prefácio em mente, é fácil inferir a importância de ler e analisar com cuidado o diálogo intermidiático construído em "the task of the translator of antigone".

\section{A TAREFA DA TRADUTORA}

A tradução do título do prefácio é o primeiro desafio para qualquer um(a) que encare a leitura da peça. A palavra de gênero comum "translator" só pode, em português, 
ser marcada pelo masculino "tradutor" ou feminino "tradutora". Aqui, orientados pelos estudos da tradução feminista, optamos pela versão a tarefa da tradutora de antígona. Além disso, é necessário atentar para o dado óbvio de que Carson retoma com o seu "task of the translator" o título do ensaio famoso de Walter Benjamin, Die Aufgabe des Übersetzers, de 1923, citado aqui na tradução de Susanna Kampff Lages, de 1998. Tal escolha será discutida adiante.

$\mathrm{Na}$ introdução do livro Gender in translation (Routledge, 1996), Sherry Simon conta a gênese do que ela chama tradução feminista canadense com a participação das críticas e tradutoras Susanne de Lotbinière-Harwood, Barbara Godard e Kathy Mezei, escrevendo textos inovadores sobre tradução como prática feminista (Simon, 1996, p. 8). Tal prática (que começa a ganhar sistematização nos anos 1980) constrói um olhar para a linguagem não apenas como veículo, mas como propósito em si mesma. O que esse grupo de estudiosas, que frequentemente não são só tradutoras, mas também críticas e escritoras, empreende é uma construção de novas estratégias de linguagem. É por isso que a releitura de mitos clássicos vai figurar como ponto central na crítica literária feminista como possibilidade de investigar inovações formais capazes de impactar o imaginário cultural e social. Nessas práticas, o comprometimento em relação ao projeto de tradução supera a ideia de fidelidade ao/à autor(a) ou ao texto. Propostas como a de Carson, por exemplo, desestabilizam de modo bastante claro o panorama eminentemente masculino da tragédia ática, que, apesar disso, produziu peças com protagonistas mulheres de enorme impacto, a ponto de as peças em que figuram personagens como Electra, Medeia, Clitemnestra e Antígona superarem em popularidade as peças em que personagens mulheres são menos preponderantes. Antígona é, portanto, uma peça muito propícia para recriação por uma poeta e dramaturga alinhada com a estética da tradução feminista, como veremos.

Sob esta perspectiva e considerando a já mencionada intertextualidade explícita do título do prefácio com o ensaio de Walter Benjamin, parece relevante pensar a metáfora que o autor alemão estabelece para o texto original como uma circunferência na qual toca o texto traduzido como uma reta em direção ao infinito:

Sendo assim, o que resta de significativo para o sentido na relação entre tradução e o original pode ser apreendido numa comparação: da mesma forma como a tangente toca a circunferência de maneira fugidia e em um ponto apenas, sendo esse contato, e não o ponto, que determina a lei segundo a qual ela continua sua via reta para o infinito, a tradução toca fugazmente, e apenas no ponto infinitamente pequeno do sentido do original, para perseguir, (...) sua própria via no interior da liberdade do movimento da língua (Benjamin, 1998, p. 117).

A tradução é, nesta perspectiva, o exercício que se faz a partir de um ponto de encontro, comum aos dois textos e que desencoraja uma abordagem centrada na ideia hierárquica de fidelidade e traição (que, por sua vez, não deixa de ser também ela gendered, já que o tradutore tradittore é masculino e as belles infidèles são femininas). 
A partir desta reflexão, é possível sustentar que o prefácio de Carson oferece pistas valiosas sobre o projeto de tradução da dramaturga, já que é interlocução direta da tradutora com a personagem Antígona, personagem em estado de desobediência civil ao tentar enterrar o corpo do irmão Polinices contra as ordens do rei Creonte. E mais, personagem mulher que aparece na peça em franca batalha pela e na linguagem contra uma personagem homem (a primeira fala de Creonte ilustra a dimensão que a linguagem assume no conflito da peça: "here are Kreon's verbs for today / Adjudicate / Legislate / Scandalize / Capitalize / here are Kreon's nouns / Men / Reason / Death / Ship of State / Mine", ao que o coro responde “"mine' isn't a noun", recebendo de Creonte a resposta simbólica "it is if you capitalize it". Uma vez que, ao longo de toda a peça, Carson evita o uso de maiúsculas no início de versos exceto nesta passagem de Creonte e nas ocorrências de substantivos como Men e Death, presentes em sua lista, o tirano instaura aqui a assimetria discursiva homem/mulher, rei/ súdita dissidente, maiúsculas/minúsculas, Razão/Traição.

Colocar Antígona como interlocutora em sua carta é também criar um diálogo com outros dramaturgos que já colocaram essa personagem em cena e, consequentemente, tiveram que lidar com (ou ignorar) as questões de gênero construídas pelo texto teatral. Há também, na remoção da personagem do contexto singular de cada encenação ou de cada versão da peça, o alçamento de sua essência trágica a uma condição de transubjetividade, de modo que Antígona passa a pairar sobre suas manifestações específicas e pode ser colocada em diálogo. O vocativo "dear Antigone" inaugura uma conversa na qual é preciso recuperar como outros encenadores/dramaturgos/homens pensaram sua existência, mesmo que fictícia. Esse diálogo dá abertura para pensar o comprometimento de Anne Carson com um projeto de tradução específico na escrita de Antigonick.

O formato do prefácio em carta também impõe outra questão: com quem exatamente fala a tradutora do texto dramático? Carson nos obriga a ter em mente tanto a tradição literária quando a tradição teatral, composta pela confluência intersemiótica instaurada no espetáculo por elementos cênicos e pela presença de corpos ao vivo - do elenco de atores/ atrizes e técnicos(as) e do público. A peça encenada é um caldeirão de referências que se materializam em cena e sempre de maneiras diferentes a cada dia de espetáculo.

Uma vez que dramaturgos/encenadores modernos como Brecht e Anouilh só puderam ter acesso à representação dos clássicos em cena tal qual estes têm sido montados nos últimos séculos, é necessário investigar o impacto da preponderância do texto escrito sobre suas escolhas. Por tal motivo, é caro a essa discussão o conceito de tradução intersemiótica tal qual recuperado por Claus Clüver, que propõe que o texto teatral deve ser ressignificado para a cena:

o conceito de "tradução intersemiótica" soa melhor se restringido a textos (em qualquer sistema sígnico) que, em primeiro lugar, oferecem uma representação relativamente ampla (mesmo que jamais completa) do texto-fonte composto num sistema sígnico diferente, numa forma apropriada, transmitindo certo sentido de estilo e técnica e incluindo equivalentes de figuras retóricas (Clüver, 1997, p. 43). 
Pode-se dizer, a partir da citação acima, que a representação dos clássicos será um caso de tradução intersemiótica, porque envolve um processo de transposição do texto clássico, que só é acessado pela leitura e portanto em fragmentos de significação, já que se encontram distantes das condições iniciais de representação, para a cena. Parece particularmente interessante pensar a tradução de Anne Carson como composição de cenas (em suas naturezas imagéticas e sonoras). Por conseguinte, a tradução do grego clássico é vista como uma passagem para o inglês considerando o sistema linguístico, o gênero literário (texto teatral, tragédia) e a tradição intersemiótica formada por experiências de encenações anteriores. Tudo isso se processa, no caso específico de Antigonick, com um componente adicional de autoconsciência do texto traduzido como tradução, colocando em evidência sua natureza secundária e paródica (no sentido etimológico com que Haroldo de Campos caracteriza a tradução, ou seja, como canto paralelo). Um dos melhores exemplos desse procedimento é a fala de Eurídice, já mencionada acima, que mistura a própria fala da personagem na versão de Carson com sua consciência de ser personagem e de ter apenas uma fala em Sófocles, aliado a sua última fala, em forma de rubrica dentro do texto (seguida por rubrica de fato, autocanceladora).

Esta formação de uma tradição intersemiótica inscreve o texto traduzido num tempo histórico específico, como prática social "datada" e exige que se reflita sobre o projeto de tradução com o qual a tradutora se compromete, embora não deixe de refletir sobre sua natureza originalmente antiga, fazendo confluírem os tempos da nova encenação com (todos) os tempos e locais anteriores em que a peça foi encenada. Nesse sentido o começo do prefácio "não que a gente queira entender tudo/ ou mesmo entender alguma coisa/ a gente quer entender uma outra coisa", ${ }^{2}$ parece sintetizar os propósitos das estratégias de tradução como reescritura.

$\mathrm{Na}$ estruturação do pensamento ocidental, majoritariamente binário, de raízes iluministas, colocar em pauta problemáticas como o tabu do incesto ("e um outro irmão que tu ama tanto que tu quer pegar ele"), as relações de parentesco ("ter um pai que é ao mermo tempo teu irmão"), a força da linguagem contra o rei ("uma paródia da lei e da língua de Kreon"), é dialogar de perto com grandes expoentes do pensamento como Lévi-Strauss, Hegel, Freud. Ao citar, no prefácio, Hegel, que classifica a mulher como "a eterna piada da comunidade", Anne Carson alude a uma tradição do pensamento sobre o trágico tal qual formada por pensadores homens até meados do século XX (quanto a isso, cf. Leonard, 2015, especialmente o capítulo 4, "Tragedy and Gender").

As referências são constantemente emolduradas pela ironia, como no caso da fala de George Eliot que julga Antígona "um exemplo de intelecto masculino e senso moral". Eliot é na verdade Mary Ann Evans (1819-1880), uma escritora que precisou, como tantas outras

\footnotetext{
${ }^{2}$ Todas as citações do prefácio em português foram retiradas da tradução da poeta Adelaide Ivánova, listada nas referências bibliográficas. Como proposta, a tradução de Ivánova atualiza a poética de Carson em um projeto específico, mas optamos por utilizá-la aqui por se tratar justamente de uma tradução feita por uma mulher. Na publicação em que ela aparece, figuram também duas outras traduções, que dão ensejo a um bom índice de comparação quanto às escolhas e projetos específicos.
} 
artistas no século XIX, usar um pseudônimo masculino para ser encarada com seriedade por essa mesma tradição a que estamos nos referindo.

Esta seção tentou demonstrar que o prefácio é construído a partir de um diálogo com a tradição grega clássica via texto literário, com a tradição de representação/recepção do teatro clássico e com uma tradição artística mais ampla, intermidiática, que tem como paradigma o pensamento tal como ele foi formulado, moldado e materializado por uma tradição eminentemente masculina.

\section{ANTÍGONA REVISITADA}

Tratando-se da representação dos clássicos e do estudo de sua recepção, existem questões inevitáveis como: de que maneiras Antigone foi lida e é lida? Como se traduzia e traduz Antigone? E ainda: como se montou e é montada a peça? Já que estas são questões norteadoras no trabalho de tradução de Anne Carson, não surpreende que apareçam no prefácio duas representações de Antigone para o teatro: uma em que a personagem está com uma porta amarrada nas costas, executada por Bertolt Brecht (A Antígona de Sófocles, 1948, baseada na tradução de Hölderlin da peça grega), e outra apresentada aos líderes da resistência francesa em 1944, montada por Jean Anouilh (Antigone, 1942). Ao citar as duas reescrituras/reencenações, a dramaturga evoca uma tradição da representação da peça de Sófocles, antes de apresentar a sua própria versão. Tal relação dialética, já longamente explorada nos estudos de recepção dos clássicos, impõe necessariamente que o sentido da obra de chegada, da reescrita, seja resultante da acumulação de sentidos que suas recepções anteriores promoveram:

A reescritura age num duplo sentido: ao mesmo tempo que traz à luz um texto, acentuando sua importância para a história da literatura e sua condição de clássico que resiste ao tempo, o faz a fim de acrescentar-lhe algo, preencher espaços abertos pelo texto mas não suficientemente explorados. A reescritura faz brotar o novo do já existente; paradoxalmente (ao menos na aparência), ela é criação na medida em que é repetição (Pascolati, 2006, p. 1862).

Na construção de sua própria reescritura, por meio da tradução, Carson propõe que Brecht foi "o que melhor te [Antígona] entendeu”. Para Carson, a porta amarrada nas costas faz da personagem uma pessoa cansada, desastrada e estranha, porém o objeto pode ser proveitoso em situações em que não existem entradas ou saídas óbvias. O corpo de Antígona na peça de Brecht é aquele que abre (cria, cava) os próprios caminhos, criando escapes para fora da normalidade e da lei vigente. É um corpo comprometido com noções próprias e compartilhadas de lei e justiça que luta para devolver o corpo do irmão morto à terra, mesmo que isso signifique "costurar tu mesma na tua própria mortalha usando a linha mais fina".

Enquanto na reescritura de Brecht Antígona e sua irmã Ismene são chamadas apenas de Segunda e Primeira, não sendo em nenhum momento identificadas pelo nome, para Carson, por outro lado, ambas estão mais próximas de apresentarem angústias centrais da 
peça de Sófocles. É possível pensar a escolha do dramaturgo a partir do que Anne Ubersfeld chama de "explosão do personagem", ou seja,

não apenas como consciência centralizadora mas como sujeito de um discurso que só pertence a ele; trata-se de quebrar não apenas a ilusão de um psiquismo que preexistiria ao discurso, mas a ilusão de um discurso que seria propriedade de um personagem determinado (Ubersfeld, 2002, p. 34).

O esforço de Brecht parece seguir no caminho de comprometer a noção de indivíduo (Antígona) para deixar emergir motivações psicológicas e jogos de relações mais sutis, implodindo a noção de sujeito transcendental para posicionar Antígona num conflito social que pode ser aquele do mundo grego antigo, esse em que o dramaturgo está inserido de Segunda Guerra Mundial ou este de 2018. Sem que, com isso, os diferentes momentos históricos percam suas particularidades, joga-se luz sobre os pressupostos políticos para revelar a ligação objetiva entre os tempos das representações. Mais uma vez, é sintomático que Carson dirija-se a Antígona em sua carta-prefácio, ela, agora, transubstanciada de personagem mítica em um acúmulo palimpsêstico de todas as suas versões paralelas e anteriores em si mesma.

Para Anne Carson, o dramaturgo alemão conseguiu captar as motivações da personagem e traduzi-las num elemento cênico: a porta amarrada nas costas. É um caso que poderia ser lido a partir do conceito de tradução intersemiótica. Pensar a tradução intersemiótica é relevante no sentido em que o texto clássico precisa materializar-se em condições de produção diversas do seu contexto inicial: “(...) o texto clássico é não apenas um objeto desligado de suas condições originais de produção (é o caso de qualquer obra literária cujo público mudou), mas também se vê obrigado a conviver com novas condições de produção" (Ubersfeld, 2002, p. 17). O não-dito textual (a porta amarrada nas costas), formulado pela e na encenação, é um exemplo de tradução intersemiótica de marcas características de uma personagem, acessadas pela leitura do texto, em elemento cênico visual.

No prefácio, Carson anuncia a reconfiguração de metáforas funcionando como novas entradas (portas) para o texto. A imagem da porta, instaurada por Brecht, torna-se metáfora para o próprio processo tradutório, representando abordagens inaugurais em relação ao texto original que culminam na criação de Antigonick. Rasgar o papel de parede e cavar buracos - referências a falas de Samuel Beckett e John Ashbery no prefácio - são também metáforas para a busca cada vez mais aprofundada daquilo que se esconde no texto e precisa escorrer para fora. É preciso cavar um buraco para enterrar o corpo do irmão, é preciso cavar buracos nos clássicos para achar novos caminhos por onde percorrer. As referências imagéticas aparecem profusamente no prefácio e podem ser lidas como reconfigurações da relação da tradutora com o texto de Sófocles; propõem-se como alternativas às conhecidas metáforas que aproximam tradução e mulher, unidas pelo mito da "queda", da expulsão do paraíso, do que é puro, original, um estado pré-Torre de Babel e, consequentemente, da necessidade angustiante de tradução (lembremo-nos, mais uma vez, do traduttore, sempre traditore e das infidèles, sempre belles). 
Uma vez que as metáforas constituem algumas das principais formas de apreensão e elaboração da realidade, elas precisam ser urgentemente revisitadas. Esse exercício é ainda mais urgente dentro dos estudos feministas, que colocam em xeque a maneira com que, de elementos concretos como o útero, derivam o feminino, a imagem da terra que recebe a semente, o elemento passivo versus o pênis, o masculino ativo, aquele que fecunda, o phallus simbólico. Essa iconografia simplifica violentamente a complexidade das relações entre as pessoas e oculta dinâmicas de poder ainda atuantes. Sendo Antigonick uma peça de tensionamento das questões de gênero em que uma mulher de palavra em desobediência civil (Antígona) investe contra o poder do Estado (rei Creonte, embora este comporte-se, também, como um típico tirano inseguro e paranoico da tragédia ateniense), ${ }^{3}$ as metáforas que constituem as noções sobre o corpo da mulher são de importância central.

Por outro lado, a peça Antigone de Jean Anouilh aparece no prefácio como motivo de tédio - "eu não sei a cor dos teus olhos/ mas posso imaginar tu girando eles com tédio". Esse juízo de valor orienta a leitura de Antigonick mais em direção ao trabalho de Brecht do que do dramaturgo francês, o que por si só sugere com qual tradição Carson quer se relacionar em seu trabalho como tradutora. Não é possível ler a "virada de olhos" de Antígona para a encenação de Anouilh como reprovação de uma peça construída para endereçar conflitos próprios ao contexto histórico de sua representação. Sobre o teor político da reescritura do francês, Sônia Pascolati assim discorre:

Ismene opta pela vida, mesmo que tenha de dobrar-se a contingências. Antigone opta pela liberdade, mesmo que tenha de morrer por isso. Metaforicamente, o diálogo das irmãs pode ser lido como uma caracterização da posição assumida por colaboracionistas e resistentes, destacando o medo dos primeiros e o destemor dos últimos (...) Seu ato de desobediência equivale ao dos franceses que, timidamente, rasgam cartazes de propaganda nazista (Pascolati, 2006, p. 1864).

A impossibilidade se justifica porque também a peça de Brecht não deixa dúvidas sobre seu comprometimento com o contexto político em que foi montada. O que parece mais inaceitável para Anne Carson no trabalho do francês é a construção de um rei menos tirânico do que o de Sófocles e o de Brecht: "a Antígona brechtiana tem a clara intenção de evidenciar a guerra. Creonte é um tirano implacável que procura controlar seus conselheiros (Coro) com ameaças e enganar o povo com festas e falsas esperanças. Creonte volta da guerra cônscio de tê-la perdido, mas esconde a verdade de todos" (Pascolati, 2006, p. 1865). A partir dessa hipótese, a escolha de Jean Anouilh deixaria de adensar as relações de poder profundamente ligadas às questões de gênero na peça - uma pista para o tédio que causaria a encenação em Antígona. Em Antigonick, a palavra mulher aparece cinco vezes, estando quatro dessas ocorrências na fala de Creonte, em passagens como: "I will not be worsted by a woman" (Carson, 2012, p. 20). Não resta dúvida que a relação dos dois personagens está pautada por dinâmicas de poder que têm a diferenciação de gênero como centro.

\footnotetext{
${ }^{3}$ Cf. Gonçalves, 2018.
} 
Se para Brecht e Anouilh, a questão fundamental da peça de Sófocles parece ser a resistência de uma pessoa (Antígona) perante o poder esmagador do Estado (Creonte ou Hitler no contexto de Segunda Guerra), para Anne Carson - inserida numa comunidade cultural de formação dos estudos feministas - a agência da personagem não pode ser entendida sem levar em consideração discussões sobre a condição e corpo de mulher de Antígona que existe, desta forma particular, no mundo. Sendo o corpo - o gestual, as relações físicas - um elemento permanente de funcionamento teatral, conforme postulado por Ubersfeld, é imprescindível pensar o teatro a partir do que os corpos têm de particularidades, neste caso marcado pelo fato inegável de Antígona ser uma mulher.

Uma leitura que traz à tona o tensionamento explícito das questões de gênero pode ir ao encontro do que Anne Ubersfeld chamou de leitura da história em três níveis: pensar sobre o referente histórico do/a escritor(a) para chegar a sua questão fundamental; compreender através de quais camadas de sentido nos chega o texto clássico, formando as tradições de leitura; construir, na história de hoje, o sentido que dará vida ao texto para nós (Ubersfeld, 2002, p. 25). Para chegar ao sentido para nós, propõe-se uma re-leitura ou, nos termos de Anne Ubersfeld, uma des-leitura do clássico grego:

Ler hoje é des-ler o que foi lido ontem - não que essa leitura tenha se tornado "falsa" mas é que não é mais para nós. O avanço das ciências humanas nos permite compreender que a obra clássica não é mais um objeto sagrado, depositário de um sentido oculto, como o ídolo no interior de um templo, - mas, antes de tudo, a mensagem de um processo de comunicação. Por esse viés a relatividade histórica das leituras se impõe ao pensamento (Ubersfeld, 2002, p. 12).

Portanto, analisar o prefácio tendo em vista o diálogo intermidiático que Anne Carson constrói em forma de carta em versos endereçada à personagem Antígona é uma estratégia para entender o projeto de tradução da dramaturga, identificando com quais trabalhos anteriores ela se aproxima na escrita de Antigonick e, sobretudo, quais ecos políticos a autora pretende que nós escutemos na voz de Antígona.

\section{O QUE PODE NOS DIZER O SILÊNCIO?}

A partir das referências às encenações de Bertolt Brecht e Jean Anouilh, percebe-se que Antigonick é uma peça que pretende, de forma inaugural, preencher os espaços deixados pelo texto de Sófocles, tendo como estratégia fundante o tensionamento das questões de gênero. Ao comparar o trabalho de Carson ao dos dois dramaturgos, pode-se perceber que a tradução como recriação forma-se a partir do agrupamento de "muitos pedacinhos de silêncio". A citação de John Cage, que aparece no prefácio, aproxima os "pedacinhos de silêncio" ao que não foi lido/traduzido anteriormente da peça de Sófocles - considerando que as problemáticas destacadas por Anne Carson (como o tabu do incesto e as questões de gênero) já existiam, em potencialidade, no texto grego clássico. 
Re-construir a partir do que não foi dito é a estratégia por excelência da reescritura dos clássicos e, também, procedimento de interesse para a teoria da tradução. Walter Benjamin, na construção de sua própria teoria, posiciona a ideia de processo tradutório como recomposição de fragmentos preexistentes:

Da mesma forma como os cacos de um vaso, para serem recompostos, devem encaixar-se uns aos outros nos mínimos detalhes, mas sem serem iguais, a tradução deve, ao invés de procurar assemelhar-se ao sentido do original, conformar-se amorosamente, e nos mínimos detalhes, em sua própria língua, ao modo de visar do original, fazendo com que ambos sejam reconhecidos como fragmentos de uma língua maior, como cacos são fragmentos de um vaso (Benjamin, 1998, p. 115).

No mesmo texto, Benjamin vai usar metáforas caras à teoria musical para afirmar que a tradução deve ecoar sua própria intenção enquanto harmonia e enquanto complemento da língua na qual se comunica, e não como reprodução de sentido, a fim de ressoar a obra estrangeira. A possibilidade de aproximação entre John Cage e Benjamin, justificada no texto de Carson, nos faz pensar que assim como John Cage esteve atento à escuta dos silêncios, a tradutora deve estar disposta a ecoar a composição de uma harmonia própria que se faz na recomposição de pedaços sonoros e silenciosos preexistentes - da tradição intersemiótica de Antígona de Sófocles.

A recomposição de Benjamin liga-se, facilmente, à ideia de re-visão de Adrienne Rich, cara à crítica literária feminista, com numerosos exemplos na poesia de Audre Lorde, Alicia Ostriker, Silvia Plath - apenas para nos restringirmos a uma tradição em língua inglesa da qual Anne Carson faz parte. Para Rich, re-visão é:

(...) o ato de olhar para trás, de ver com um novo olhar, de entrar em um texto a partir de uma nova direção crítica - é, para nós, mais do que um capítulo na história cultural: é um ato de sobrevivência (...) Uma crítica radical da literatura, feminista em seu impulso, consideraria a obra prioritariamente como um indício de como vivemos, como temos vivido, como temos sido levadas a nos imaginar, como a nossa linguagem tem nos aprisionado ou liberado, como cada ato de nomear tem sido, até agora, uma prerrogativa masculina e como podemos começar a enxergar e a nomear - e, portanto, a viver - de uma nova maneira (Rich, 2017, p. 66-67).

Nesse sentido, o projeto de tradução de Carson gira em torno de formas diferentes de re-visitar os clássicos, o que revela o caráter indiscutivelmente político de sua criação. A referência à composição 4'33" de John Cage é uma pista intermidiática que, da mesma forma que a personagem Antígona, inspira Carson não ao silêncio, mas à escuta atenta dos acontecimentos principalmente "quando tudo que for normal/musical/cauteloso/ convencional ou piedoso nos for tirado" (prefácio de Antigonick). Assim, a tarefa da tradutora 
consiste em não deixar que a potencialidade da voz (especificamente do grito) de Antígona se perca, e para tanto é preciso fazer com que os gritos façam sentido hoje e aqui, sendo esses dêiticos preenchidos de acordo com as circunstâncias - e preenchidos, leia-se, com a extensão do corpo de mulher de Antígona que são seus gritos, de ontem e de hoje. Sob esta perspectiva, o/a leitor(a) e espectador(a) não são mais virtuais, têm necessariamente uma realidade empírica, geo e temporalmente localizada, e por isso mesmo a tradução está fadada a passar, trabalhando em função da pervivência do texto original:

(...) na sua "pervivência" (que não mereceria tal nome, se não fosse a transformação e renovação de tudo aquilo que vive), o original se modifica. Existe uma maturação póstuma mesmo das palavras que já se fixaram: o que à época do autor pode ter obedecido a uma tendência de sua linguagem poética, poderá mais tarde esgotar-se; tendências implícitas podem surgir como novas da forma criada. Aquilo que antes era novo, mais tarde poderá soar gasto; o que antes era de uso corrente pode vir a soar arcaico (Benjamin, 1998, p. 108).

Para garantir a pervivência do texto original, a tradução deverá estar atenta ao/à espectador(a), o/a responsável pela reintegração do sentido. A teatralização dos clássicos se refaz pelo investimento do espectador na representação (Ubersfeld, 2002, p. 33). Portanto, é impossível, ao mesmo tempo, levar em conta o/a espectador(a) e ignorar a discussão sustentada pelos estudos feministas neste momento de virada epistemológica em que vivemos e pesquisamos. Como ler a tradução de Anne Carson do texto de Sófocles sem levar em consideração a crítica literária feminista? Não nos parece possível, nem mesmo útil à pervivência de Antígonas contemporâneas.

\section{REFERÊNCIAS}

BENJAMIN, Walter. A tarefa do tradutor. In: . Escritos sobre mito e linguagem. Org. Jeanne Marie Gagnebin. Trad. Susana Kampff Lages. São Paulo: Editora 34, 1998.

CARSON, Anne. Antigonick. New York: New Directions, 2012.

CARSON, Anne. Bakehai. London: Oberon Books, $2015 \mathrm{a}$.

CARSON, Anne. Antigonick. Paperback edition. New York: New Directions, 2015b.

CARSON, Anne. If Not, Winter. Fragments of Sappho. New York: Alfred A. Knopf, 2002.

CARSON, Anne. Electra. Oxford: University Press, 2001.

CLÜVER, Claus. Estudos interartes: conceitos, termos, objetivos. Revista Literatura e Sociedade, v. 2, n. 2, p. 37-55, 1997.

GONÇALVES, Rodrigo T. Édipo, Creonte e a paranoia dos tiranos. Coletivo Praxis. Disponível em: https://coletivopraxis.com.br/2018/10/31/edipo-creonte-paranoia-tiranos/. Acesso em: 27 nov. 2018. 
IVÁNOVA, Adelaide. a tarefa do tradutor de antígona (tradução buana). In: MACIEL, Sergio. 3 traducões para o "task of the translator" da Antigonick de Anne Carson. Disponível em: https:/ / escamandro.wordpress.com/2017/01/13/3-traducoes-para-o-task-of-the-translator-daantigonick-de-anne-carson/. Acesso em: 5 ago. 2018.

LEONARD, Miriam. Tragic Modernities. Harvard: University Press, 2015.

PASCOLATI, Sônia A. V. Faces de Antígona no teatro moderno. Revista Estudos Linguísticos, v. 35, p. 1861-66, 2006.

RICH, Adrienne. Quando da morte acordamos: a escrita como re-visão. Trad. Susana Funck. In: BRANDÃO, Izabel et al. (Org.). Traduções da cultura: perspectivas críticas feministas (1970-2010). Florianópolis: EDUFAL, Editora da UFSC, 2017. p. 64-84.

SIMON, Sherry. Gender in translation: cultural identity and the politics of transmission. New York: Routledge, 1996.

UBERSFELD, Anne. A representação dos clássicos: reescritura ou museu. Trad. Fátima Saadi. Folhetim Teatro do Pequeno Gesto, n. 13, p. 9-37, 2002. 
